Please quote as: Zogaj, S.; Bretschneider, U. \& Leimeister, J. M. (2014): Managing Crowdsourced Software Testing - A Case Study Based Insight on the Challenges of a Crowdsourcing Intermediary. In: Journal of Business Economics (JBE) (DOI: 10.1007/s11573-014-0721-9), Erscheinungsjahr/Year: 2014. 


\title{
Managing crowdsourced software testing: a case study based insight on the challenges of a crowdsourcing intermediary
}

\author{
Shkodran Zogaj • Ulrich Bretschneider • \\ Jan Marco Leimeister
}

(C) Springer-Verlag Berlin Heidelberg 2014

\begin{abstract}
Crowdsourcing has gained much attention in practice over the last years. Numerous companies have drawn on this concept for performing different tasks and value creation activities. Nevertheless, despite its popularity, there is still comparatively little well-founded knowledge on crowdsourcing, particularly with regard to crowdsourcing intermediaries. Crowdsourcing intermediaries play a key role in crowdsourcing initiatives as they assure the connection between the crowdsourcing companies and the crowd. However, the issue of how crowdsourcing intermediaries manage crowdsourcing initiatives and the associated challenges has not been addresses by research yet. We address these issues by conducting a case study with a German start-up crowdsourcing intermediary called testCloud that offers software testing services for companies intending to partly or fully outsource their testing activities to a certain crowd. The case study shows that testCloud faces three main challenges, these are: managing the process, managing the crowd and managing the technology. For each dimension, we outline mechanisms that testCloud applies for facing the challenges associated with crowdsourcing projects.
\end{abstract}

Keywords Crowdsourcing - Crowdsourcing business model · Intermediary · Software testing - Case study

JEL Classification $\mathrm{M} 15 \cdot \mathrm{M} 21 \cdot \mathrm{O} 32$

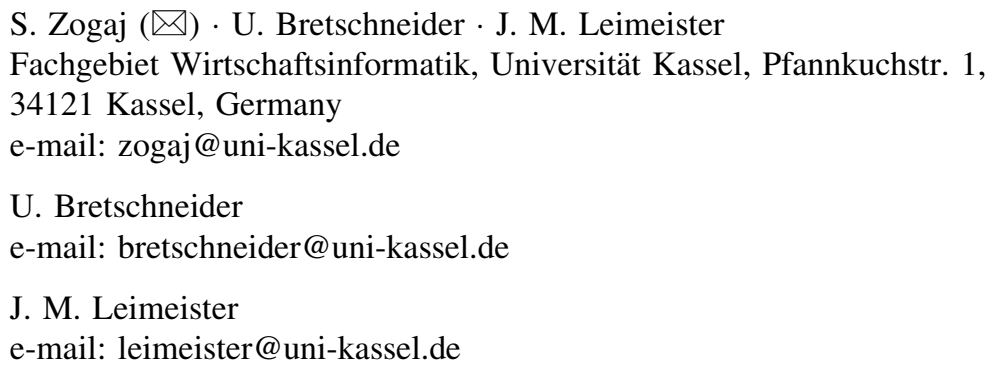




\section{Introduction}

Faced with an increasingly dynamic environment primarily due to advancing competitiveness, shorter product and innovation cycles (Ernst 2002), increasing complexity of problems as well as customers' desire to participate in the product design and development process (Füller and Matzler 2007), more and more organizations are increasingly on the lookout for new ways of acquiring and sourcing knowledge from outside the boundaries of their units, functions, or even outside their organization (Jain 2010; Walmsley 2009). In this connection, new information technologies, particularly the Internet as an immersive and multimediarich technology with low costs of mass communication, come to the fore as they allow companies to reach and interact with a large number of external sources in a more (cost) effective as well as interactive manner. Thereby, it is now possible for companies to reach out to the masses (Vukovic 2009), and open tasks and functions "once performed by employees and outsourcing [these] to an undefined (...) network of people in the form of an open call" (Howe 2006b). This form of sourcing is referred to as 'crowdsourcing' and was first coined in 2006 by Jeff Howe in the Wired magazine (Howe 2006b).

Based on the concept of outsourcing, the term crowdsourcing emerged, referring to the outsourcing of corporate activities to an independent mass of people ("crowd") (Howe 2008). The crowd collectively takes over tasks-such as generating innovation ideas, solving research questions or pattern recognition-that it can complete in a cheaper or better way than machines or experts. Due to the pervasiveness of the Internet and its nearly ubiquitous presence in the recent past, crowdsourcing has gained great popularity, and numerous companies have used this concept for performing different tasks and value creation activities. For instance, software companies, such as Fujitsu-Siemens (Füller et al. 2011), IBM (Bjelland and Wood 2008) or SAP (Leimeister et al. 2009), have leveraged the wisdom of crowds for innovation development by using ideas competitions. In these cases, hundreds of people submit innovative ideas and solutions regarding the underlying issue, where the best ideas and solutions are then rewarded afterwards. In the frame of crowdsourcing, companies can either directly interact with the crowd-like in the depicted examples - or they can use intermediaries that mediate between the crowd and the company.

Prominent examples of intermediaries in a crowdsourcing model are InnoCentive, oDesk or Amazon's Mechanical Turk, allowing companies to offer tasks on their platforms to a mass of users on the Web that can be solved for a specific fee (Jeppesen and Lakhani 2010; Leimeister 2010). Apart from these renowned examples, numerous other intermediaries have emerged due to a high level of demand by companies for crowdsourcing services. Thus, crowdsourcing can also be considered as an enabler for new business models, i.e., for intermediaries in a crowdsourcing model (Chanal and Caron-Fasan 2010).

Despite its popularity, there is still comparatively little well-founded knowledge on crowdsourcing, particularly with regard to crowdsourcing intermediaries. Emerging articles about preliminary taxonomies, typologies and categorizations of crowdsourcing (Rouse 2010; Brabham 2012; Yuen et al. 2011), about basic 
characteristics of crowdsourcing initiatives (Schenk and Guittard 2011; Vukovic and Bartolini 2010) or about the definition of crowdsourcing (Estellés-Arolas and González-Ladrón-de-Guevara 2012; Oliveira et al. 2010) highlight the noveltycharacter of this concept. Most research activities related to crowdsourcing have, however, solely focused on specific spheres of this concept such as crowdsourcing for innovation development-i.e., the realm of "open innovation" (see e.g., Chesbrough and Crowther 2006; Gassmann and Enkel 2004; Bullinger et al. 2010; Franke and Piller 2004; West and Lakhani 2008). Further, existing research articles have focused either only on companies that (intend to) implement crowdsourcing and their corresponding (theoretical) decision processes (see e.g., Afuah and Tucci 2012; Schenk and Guittard 2009) or exclusively on crowd-specific characteristics such as motivational aspects (see e.g., Brabham 2010; Kaufmann et al. 2011). Thus, profound research on intermediaries in crowdsourcing models is still missing.

We, however, believe that intermediaries play a key role in crowdsourcing initiatives as they-once hired by a company-manage the whole crowdsourcing process. They, on the one hand, interact with the crowdsourcing company with regards to appropriately framing the tasks and the corresponding solution requirements so that the crowd is able to properly solve the crowdsourced tasks. On the other hand, intermediaries are responsible for managing the crowd itself and all the activities within the crowd. These aspects suggest that crowdsourcing intermediaries face different challenges on various levels that ought to be addressed by current research. Practice and research show that crowdsourcing intermediaries are increasingly used by organizations for the development and testing of software applications - such as enterprise software, office suites, accounting software, mobile applications or websites (e.g., via the crowdsourcing intermediaries TopCoder, uTest or PASSbrains) (see e.g., Malone et al. 2011; Vukovic and Bartolini 2010; Bacon et al. 2009; Jayakanthan and Sundararajan 2011; Mao et al. 2013). Existing studies provide evidence that intermediation is challenging especially for crowdsourced software testing initiatives in the context of which companies outsource software testing tasks to a crowd (Tung and Tseng 2013; Mao et al. 2013; RiunguKalliosaari et al. 2012). Current research lacks insights of how to manage such crowdsourced software testing initiatives from an intermediary's perspective. Against the backdrop of these considerations, this paper aims to answer the following research question: What are the main challenges for crowdsourcing intermediaries associated with the mediation in crowdtesting initiatives and how does an exemplary crowdsourcing intermediary overcome these challenges?

We address these issues by conducting a case study with a German start-up intermediary called testCloud that offers software testing services for companies intending to partly or fully outsource their testing activities to a certain crowd. Being a start-up company that managed to implement more than two dozen crowdsourcing projects and generate a relatively large crowd within a year, testCloud constitutes a suitable case for attaining valuable insights regarding the management of crowdsourcing initiatives from an intermediary's perspective. The case study helps to bring more rigor to the management of crowdtesting initiatives, since the majority of them still has room for improvement, as they are most often 
realized by means of a trial and error approach. Hence, the insights help making crowdtesting more manageable and controllable.

The remainder of this paper is structured as follows: In section two, we first provide the terminological background by briefly approaching the concept of crowdsourcing as well as outlining intermediaries in a crowdsourcing model as actors that manage the relationship between crowdsourcing companies and the crowd. Within this section, we also present related work in order to utilize previously generated insights for the subsequent case study. In Sect. 3, we provide a summary of the methodology used for this research before we outline the case of testCloud. Afterwards, we present the results of the study. Finally, we draw implications for the management of crowdtesting initiatives from an intermediary's perspective before providing an outlook for future research.

\section{Theoretical background and related work}

\subsection{Crowdsourcing}

"Remember outsourcing? Sending jobs to India and China is so 2003. The new pool of cheap labor: everyday people using their spare cycles to create content, solve problems, even do corporate R \& D” (Howe 2006b, p. 1).

Crowdsourcing describes a new form of sourcing out tasks, or more accurately, value creation activities and functions. The term itself is a neologism that combines crowd and outsourcing (Rouse 2010) and goes back to Jeff Howe, who defines crowdsourcing as "the act of taking a job traditionally performed by a designated agent (usually an employee) and outsourcing it to an undefined, generally large group of people in the form of an open call" (Howe 2008). Whereas outsourcing denotes the outplacement of specific corporate tasks to a designated third-party contractor or a certain institution, within crowdsourcing the tasks are allocated to an undefined mass of anonymous people (the "crowd") who, in turn, will be rewarded for their effort of performing the tasks. Therefore, two basic elements distinguish crowdsourcing from outsourcing: an open call and a crowd (Burger-Helmchen and Penin 2010). Within crowdsourcing, participation is non-discriminatory-i.e., instead of relying on only one or a small number of designated suppliers, in the case of crowdsourcing everybody can answer to the open call (Pénin 2008). This may, for instance, include communities of individual, firms, institutions or nonprofit organizations as well as any other individuals. This is a prerequisite that enables a "crowd" to emerge, which is then (most often) characterized by a strong heterogeneity and anonymity.

The idea of crowdsourcing is to utilize the so called "wisdom of crowds" (Surowiecki 2004) and the associated benefits. This principle is based on the idea that a group of average people can-under certain conditions-achieve better results than any individual of the group. This seems to hold even if one member of the group is more intelligent than the rest of the group. Hence, crowds are capable of solving tasks much better than any expert (Jeppesen and Lakhani 2010; Leimeister 
2010). Apart from this benefit that is associated with the power of the collective intelligence, the literature lists several other advantages for firms with regard to crowdsourcing: access to a large reservoir of resources, competencies, ideas and solutions; outsourcing of failure risks due to performance-based remuneration (Burger-Helmchen and Penin 2010; Jain 2010); cost-effectiveness due to costoutcome based contracts and payments (rather than hourly wages) (Rouse 2010); and time-efficiency due to short response times (Tapscott and Williams 2007; Allison and Townsend 2012). However, there are also various disadvantages associated with crowdsourcing, such as: the risk of disclosing valuable knowledge as well intellectual property or proprietary information (Rayna and Striukova 2010), as well as the risk of obtaining either an insufficient submissions or low-quality contributions by the crowd (Leimeister et al. 2009; Hoßfeld et al. 2012). Eventually, crowd members' solutions might be difficult to exploit within the firm (Blohm et al. 2012), and there could be the risk of crowd misbehavior.

Nevertheless, crowdsourcing is enjoying increasing popularity in various domains such as IT, art, health care, electronic consuming, finance, and many others. For instance, at "Wilogo.de" or "12designer.com" crowd members design logos for companies and get rewarded for their designs. Other examples are innovation communities in different domains - such as SAPiens by SAP (software), MyStarbucksIdea by Starbucks (food sector) or Local Motors (automotive)-where the crowd generates innovative ideas and solutions either by means of collaboration within a community or by means of competition. Generally, the processing of tasks within crowdsourcing can basically be either dependently-driven or independentlydriven. In the first case, certain members from the crowd team up and work together on one joint solution. In this context, important dependencies exist between the contributions which eventually lead to the (group) solution (Afuah and Tucci 2012; Malone et al. 2010). Wikipedia would be a representative example as the contributions by the individuals creating one article are strongly interdependent. As opposed to this, in the second case (independently-driven crowd work), each member of the crowd works independently on his or her own solution to the problem. This includes, for example, the execution of micro tasks on crowdsourcing platforms such as Amazon Mechanical Turk or oDesk. A special type of independently-driven crowd works are crowdsourcing contests, such as idea competitions initiated at InnoCentive. Here, each individual from the crowd selfselects to independently work on a solution; however, only the best solution(s) out of all members is (are) rewarded (Afuah and Tucci 2012).

In both cases-dependently-driven as well as independently-driven crowd work - the process of crowdsourcing initiatives is basically identical: First, a firm or some type of institution selects specific internal tasks that it wants to crowdsource and subsequently broadcasts the underlying tasks online, i.e., onto a crowdsourcing platform. In a second step, individuals (e.g., from a certain community) self-select to work on the solution-either individually or in a collaborative manner-and subsequently submit the elaborated solutions via the crowdsourcing platform. The submissions are then assessed and-in case of successful completion-remunerated by the initiating organization. Hence, in a crowdsourcing model, at least two types of actors are engaged (see also Fig. 1): the initiating organization that crowdsources 


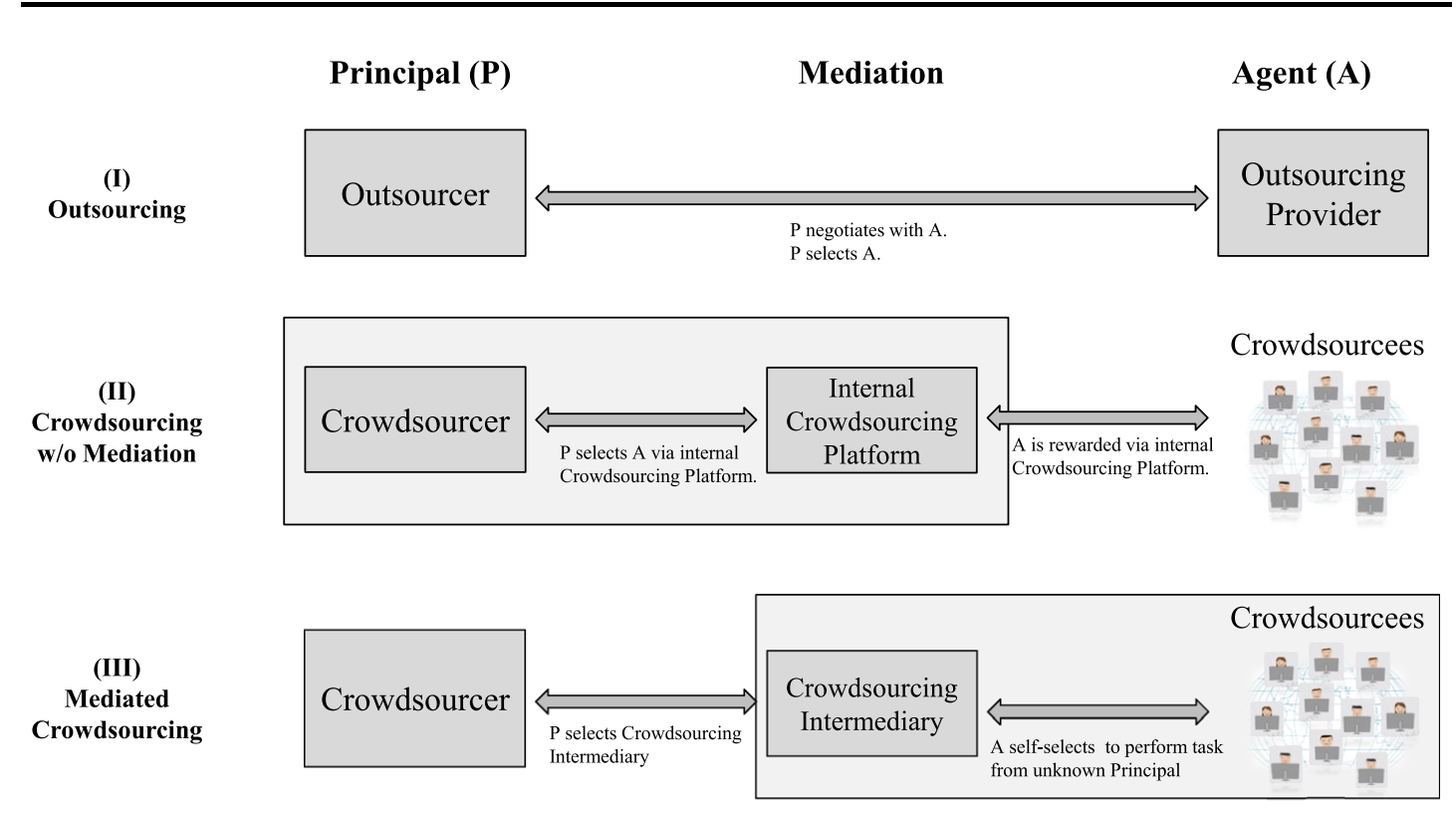

Fig. 1 Roles and mediation in crowdsourcing initiatives. (Source: adapted from Hoßfeld et al. 2012, p. 206)

certain tasks and the individuals from the crowd who perform these tasks. The first entity we denote as crowdsourcer ["system owner" (Doan et al. 2011); "designated agent" (Howe 2006a)]. The latter, the undefined contractors from the crowd, we label as crowdsourcees.

In some cases, the crowdsourcer establishes a crowdsourcing platform, which is hosted by the crowdsourcers (internal crowdsourcing platform). However, in most crowdsourcing initiatives there is also a third type of agent: the crowdsourcing intermediary. Crowdsourcing intermediaries, as the name suggests, mediate between the crowdsourcer and the crowdsourcees by providing a platform where these parties are able to interact. Hence, they hold an important role in a crowdsourcing model and may most likely be decisive for the success of a crowdsourcing initiative. Therefore, in the subsequent section, we focus on some key aspects of such intermediaries.

\subsection{Crowdsourcing intermediaries}

The remarkable rise of crowdsourcing is basically due to the development of new information and communication technologies, particularly the Internet as an immersive and multimedia-rich technology with low costs of mass communication. Especially Web 2.0 has enabled new business models to evolve and flourish-with crowdsourcing intermediaries as one of them. Crowdsourcing intermediaries are web platforms which function as marketplaces, thereby managing the relationship between crowdsourcers and crowdsourcees (Chanal and Caron-Fasan 2010). They, on the one hand, interact with the crowdsourcing company with regards to appropriately molding the tasks and the corresponding solution requirements so that the crowd is able to properly solve the crowdsourced tasks. On the other hand, 
intermediaries are responsible for managing the crowd itself and all the activities within the crowd. Literature attributes great importance to intermediaries, in general, as they enable firms to access a vast pool of resources and (social) capital. Functioning as a key element in (some sort of) a network, they help firms to overcome insufficient skills and lack of resources by connecting these with appropriate counterparts.

Drawing on the literature on social capital, Burt (2005) argues that structural holes in a network represent gaps that occur once two parties are not aware of the value they could create in case of collaboration. These holes can, however, be closed by an independent actor-or an intermediary-who creates awareness between the two parties of the value of collaboration (Kirkels and Duysters 2010). Hence, intermediaries serve as brokers who connect and link different parties-or to be more specific, they bring together knowledge seekers and knowledge suppliers (Howells 2006). Klerkx and Leeuwis (2009), Stewart and Hyysalo (2008) and Winch and Courtney (2007), amongst others, attribute several advantages to intermediaries, such as their possibility to not only connect knowledge seekers and knowledge suppliers but also to help organizations find appropriate partners for collaboration and joint projects. They also help to avoid opportunistic behavior and reduce uncertainty in a multi-entity relationship, as well as to facilitate negotiations and manage networks.

Considering the above mentioned aspects, crowdsourcing intermediaries can, thus, be considered as brokers insuring crowdsourcers (who can be considered as knowledge seekers) to connect with crowdsourcees (who can be considered as knowledge suppliers) by providing the necessary infrastructure for crowdsourcing activities. Thereby, crowdsourcers are not only granted access to a vast pool of resources and skills, but-more importantly-they also outsource risks, effort and overhead related to the management of the crowdsourcing process as well as the management of the crowd to a particular intermediary. Due to the increasing popularity of crowdsourcing in various domains over the last years, numerous crowdsourcing intermediaries have emerged. In most cases, they specialize in a certain field or in specific activities or tasks. For instance, InnoCentive enables individuals, firms and other institutions to broadcast a scientific problem via the InnoCentive platform and have the crowd solve the problem by means of an (idea) competition, whereas at TopCoder software programming tasks are posted as contests (Jain 2010). On the other hand, at Amazon's Mechanical Turk the crowd fulfills micro tasks (e.g., labeling images, classifying websites, spellchecking, etc.).

Various researchers (e.g., Zhao and Zhu 2012; Vukovic 2009; Kleeman et al. 2008; Whitla 2009) have analyzed the application of crowdsourcing platforms for different purposes and different situations, and suggest different alternatives for categorizing crowdsourcing intermediaries. Based on these insights, we identify six application fields or functions to which existing crowdsourcing intermediaries can be attributed: innovation development, design, development and testing, marketing and sales, funding and support. This dimension relates to the "part of the product and/or service lifecycle that is being crowdsourced" (Vukovic 2009, p. 687). Subsequently, we present some prominent examples of crowdsourcing intermediaries based on the mentioned attribution (see Table 1). To be noted is that, for each 


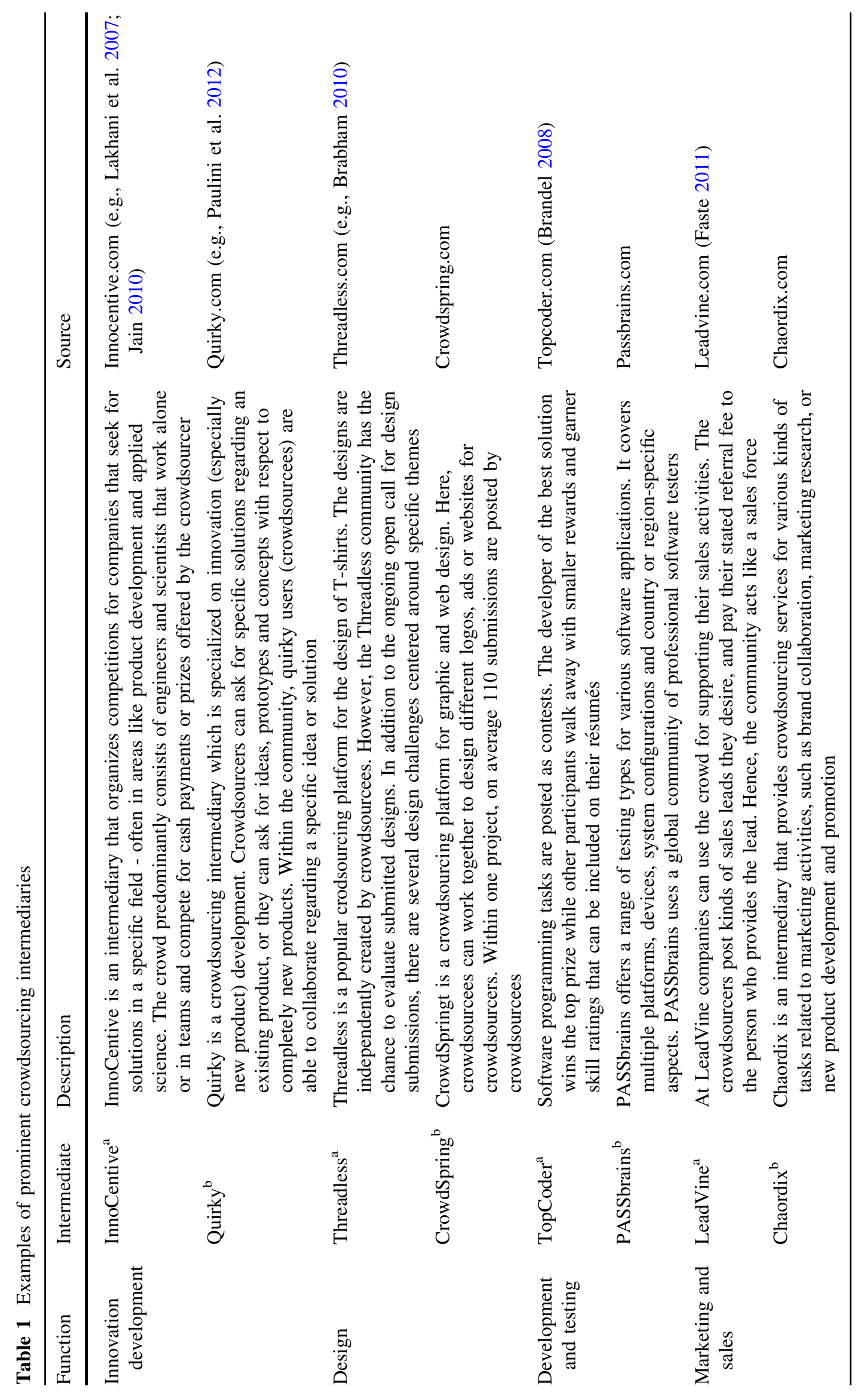




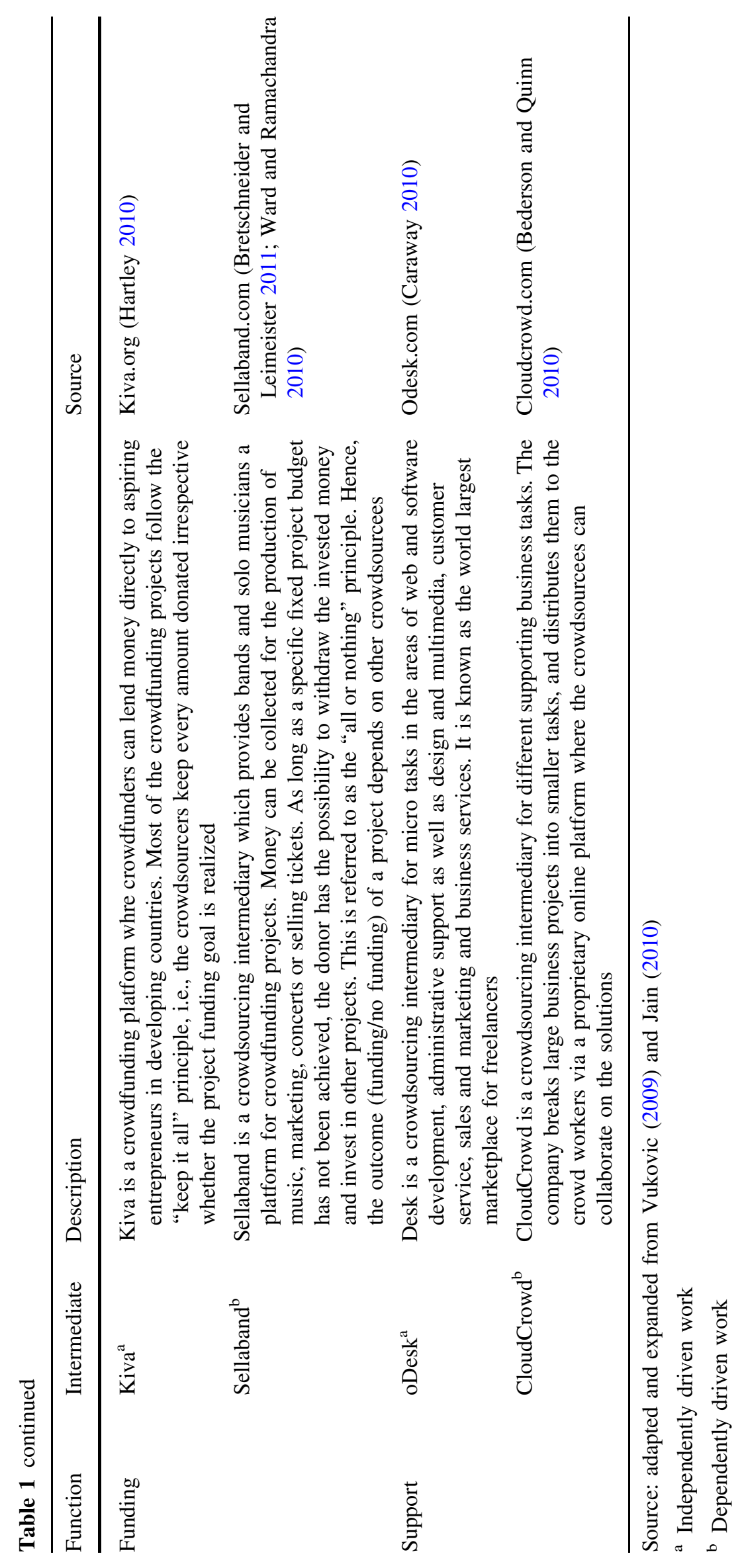


category, the work at a specific crowdsourcing intermediary can rather be dependently-driven or independently-driven - though this distinction is not always clear-cut in practice (see Sect. 2.1).

By crowdsourcing innovation development activities, firms may benefit from valuable as well as innovative ideas and solutions coming from crowdsourcees. They can crowdsource different activities within the innovation development process, such as ideation, concept development, etc. (Bretschneider 2012). Prominent examples of intermediaries in this context are InnoCentive and Quirky. Firms can also benefit from the creativity of crowdsourcees by crowdsourcing design processes-e.g., the design of logos and brands, or product modifications at Threadless and 12 designer. TopCoder and uTest are intermediaries which offer crowdsourcing services with respect to development and testing. In this connection, the crowd develops individual parts of a certain product (e.g., a software application)—or even the whole product—and performs testing activities.

Crowdsourcees can also support marketing and sales activities by, for instance, generating leads for the crowdsourcer (e.g., via LeadVine). Over the last years, several so called crowdfunding intermediaries have emerged. In the context of "crowdfunding," firms use crowdsourcing intermediaries to get access to a pool of individuals who donate sums of money to support or finance a specific project. Intermediaries in such crowdsourcing initiatives (e.g., SellaBand or Kickstarter) have-in a metaphorical sense-the role of a bank that connects investors and lenders. Finally, there are intermediaries for crowdsourcing supporting functions. These are, for example, Amazon's Mechanical Turk and oDesk. Within these platforms, crowdsourcees complete micro tasks for crowdsourcers. Micro tasks are not regarded as crucial value creation activities (such as innovation development); however, they serve as support to all the other functions.

\subsection{Related work}

Research on crowdsourcing is still in its inception. First studies on crowdsourcing have focused on specific applications of crowdsourcing, such as open innovation or human computing (Geiger et al. 2011). However, there are also some preliminary taxonomies, typologies and categorizations of crowdsourcing (e.g., Rouse 2010). Herein, the authors try to identify basic characteristics of this concept. The thereby generated insights provide first references for the management and organization of crowdsourcing initiatives. Thus, they might also be auxiliary for understanding the management of crowdsourcing from an intermediary's perspective. Therefore, we will subsequently outline such categorization systems selecting only findings that are relevant for the underlying study.

Malone et al. (2010) suggest four dimensions that are important when designing any system for collective action, hence also including crowdsourcing platforms of intermediaries: goal, structure/process, staffing and incentives. On the basis of an extensive examination of Web enabled collective intelligence systems, they found that all existing collective intelligent systems can be described by a small set of building blocks. Using an analogy from biology, Malone et al. (2010) denote the different building blocks as "genes" of collective intelligence systems. Regarding 
the question as to who performs a given task, Malone et al. (2010) differentiate between the two blocks: hierarchy and crowd. The hierarchy gene refers to the case where an activity or specific decision is undertaken by individuals inside the organization. On the contrary, if activities are realized by someone in a large group, without being assigned by someone in a position of authority, the crowd gene is enabled. With respect to the question as to why individuals perform crowdsourced tasks, Malone et al. (2010) propose three genes which comprise the various motives on a generic level: money, love, and glory. The gene of money refers to monetary incentives, such as direct payments and cash prizes. However, people are not only motivated by financial interests. Research studies show that intrinsic motives, such as enjoyment, altruism, socialization, or sense of belonging, are equally important (Lakhani and Wolf 2005). The love gene refers to such kind of motives. The desire of recognition-e.g., by peers - is also an important motivator for people to become active in certain activities (glory). By surveying the AMT platform, Corney et al. (2009) discover that contribution of crowdsourcees in crowdsourcing initiatives might be costless as well as costly.

Whereas Malone et al.'s framework is very generic in relating to every collective intelligence system, Zwass (2010) proposes a taxonomic framework as a prerequisite for theory building in co-creation research. He outlines the most salient aspects of co-creation initiatives (i.e., co-creators, task, process, co-created value), however, laying special emphasis on the dimension of process. In Zwass' article, this dimension relates to mechanisms for the governance of co-creators (i.e., crowdsourcees). Zwass (2010) presents various governance regimes-such as individual autonomy, collective norms, or adhocracy-and suggests that cocreators' incentives as well as the IT-support are key issues when structuring governance. Motivational aspects are also highlighted in Rouse (2010) study. Rouse (2010) proposes a taxonomy of crowdsourcing that consists of three dimensions, i.e., distribution of benefits, supplier capability, and forms of motivation. By reviewing the literature on crowdsourcing and especially on open innovation (e.g., Leimeister et al. 2009; von Hippel 1986), the author identifies various motives that encourage crowdsourcees to engage in crowdsourcing initiatives (e.g., altruism, self-marketing, or social status). More importantly, she relates the dimension of supplier capability with the characteristics of tasks in crowdsourcing initiatives. The higher the complexity and skills involved in the task, the more capabilities the supplier (i.e., the crowdsourcees) needs to have. Accordingly, the tasks are classified in three groups (listed with increasing difficulty): simple tasks, moderate tasks, and sophisticated tasks. Related to the same context, Schenk and Guittard (2011) classify crowdsourcing tasks into routine, complex and creative tasks.

Contrary to the presented studies, Geiger et al. (2011) analyze crowdsourcing processes. They develop a new taxonomic framework for crowdsourcing processes which "focuses exclusively on an organizational perspective and on the mechanisms available to these organizations" (Geiger et al. 2011, p. 1). By analyzing existing classifications of crowdsourcing systems [some of them already presented in this paper-e.g., Schenk and Guittard (2011) or Rouse (2010)], they identified four dimensions: preselection of contributors, accessibility of peer contributions, aggregation of contributions, and remuneration for contributions. The first 
dimension, preselection of contributors, addresses the issue if, and if so, how crowdsourcers select a certain number or a certain type of crowdsourcees. Accessibility of peer contributions (second dimension) relates to the degree to which crowdsourcees have access (i.e., modify, assess, or only view) to each other's contributions. According to Geiger et al.'s taxonomy, the aggregation of contributions (third dimension) in a crowdsourcing initiative can either be integrative, i.e., all contributions are reused for the final outcome, or selective, which means that just one or a few out of all contributions is/are selected. Finally, the remuneration for contributions (fourth dimension) can be fixed or success based.

The presented frameworks and classifications cover key issues within crowdsourcing, and they can be used to distinguish between various crowdsourcing initiatives based on the underlying dimensions. These works deal with crowdsourcing on a generic level, and most often relate to multiple concerns (apart from exceptional cases, such as Geiger et al.'s work). There are, however, very few articles that deal explicitly with crowdsourcing intermediaries-articles dealing with crowdsourcing intermediaries most often lay emphasis on the business model of such entities (e.g., Chanal and Caron-Fasan 2010). However, the issue of how crowdsourcing intermediaries manage crowdsourcing initiatives and the associated challenges has not been addresses by research yet. Based on insight from literature, it has been shown that crowdsourcing intermediaries fulfill an important function in a mediated crowdsourcing model (see Sects. 2.1, 2.2) and have to eventually manage the crowdsourcing process and all the other issues outlined in this section. But how is this explicitly done and what are the main challenges in this connection? To shed some light in this area, we subsequently present and analyze a case study with a German start-up intermediary called testCloud that offers software testing services for companies intending to partly or fully outsource their testing activities to a certain crowd.

\section{The case of "testCloud": a crowdsourcing intermediary for software testing}

\subsection{Methodology and case selection}

Given the lack of empirical research on crowdsourcing intermediaries, our primary objective was to achieve better understanding of how such intermediaries manage the mediation in a crowdsourcing model. Studying the management of crowdsourcing initiatives from an intermediary's perspective as well as the challenges associated with it demands qualitative research on the organizational level. The case study methodology is particularly useful for exploring new phenomena, such as crowdsourcing intermediaries (Bittner and Leimeister 2011; Darke et al. 1998). "Revelatory" single case studies can often shed useful light on, and provide a deeper understanding of, important issues when the available data are limited since they allow to observe, explore, and explain new phenomena within their real-life setting (Yin 2003; Steinfield et al. 2011). Thus, by thoroughly analyzing the underlying issues, we can gain a better understanding of how and why something happened as it did, and where future research should proceed (Verner and Abdullah 
2012). According to Eisenhardt (1989), as well as Yin (2003), case studies are useful when the phenomenon has not yet received appropriate ascertainment within the existing literature, and when theoretical knowledge lacks clearness and certainty with respect to the underlying issue. Crowdsourcing intermediaries exhibit the above mentioned features. Therefore, we suggest the case study approach to be suitable for investigating crowdsourcing intermediaries and the challenges associated with it.

For our study, we chose a German start-up intermediary called testCloud (website: www.testcloud.de) that offers software testing services for companies intending to partly or fully outsource their testing activities to a certain crowd. Software testing has become highly expensive in terms of time, money and other resources (Myers et al. 2011; Whittaker 2000). Further, the classical in-house testing is restricted to the knowledge of a small set of solvers and thus is limited in terms of quality and efficiency. Recognizing this, testCloud implemented a crowdsourcing business model offering software companies the possibility to outsource their testing activities to a certain crowd. With this so-called 'crowdtesting,' testCloud facilitates companies in accessing a wide pool of human resources and thereby using the collective intelligence of crowds. testCloud provides an excellent context for exploring the challenges, and understanding the internal processes, of crowdsourcing intermediaries for a number of reasons: First, the start-up company managed to implement more than two dozen crowdsourcing projects and generate a relatively large crowd within just a year. For this to work, normally, internal functions and processes must be well-coordinated. This naturally leads to the question as how these functions and processes are managed. Further, the above mentioned development of testCloud indicates that there is a high demand of companies to crowdsource testing activities as well as of individuals to work in crowd as software tests. Second, the operations, processes and procedures in start-up businesses that consist of just a few workers are, normally, more transparent and easier to asses and evaluate. This might be due to the fact that there are only a handful of decision-makers. The third reason for testCloud being a suitable case to analyze the above mentioned issue is that software testing covers a wide range of task types-from visibility tests to security tests through to usability tests-with a variety of complexity. Hence, the case study relates to the particular function of testing (see Sect. 2.2); however, it is not restricted to only one type of task, e.g., micro tasks. This broadens the focus and purview of the study.

According to Meredith, a case study-analysis "typically uses multiple methods and tools for data collection from a number of entities by a direct observer(s) in a single, natural setting that considers temporal and contextual aspects of the contemporary phenomenon under study, but without experimental controls or manipulations" (Meredith 1998, p. 442-443). Data sources for our study include three semi-structured, in-depth (personal) interviews conducted with the three founders of testCloud from early to mid-2012. At that time, testCloud consisted only of these three members, who together managed all processes associated with the company. We developed a roughly structured guideline with open questions which addressed various issue on different levels—-such as the internal processes of task allocation and IT-governance, or the build-up of the crowd and the management of 
the contributions by crowdsourcees. Each interview lasted at least $1 \mathrm{~h}$; however, we also conducted shorter interviews with one of the informants over the telephone. All interviews were recorded and subsequently transcribed. In each situation, detailed notes were taken during interviews. Among the interviewees were: (1) testCloud's Chief Sales Officer (CSO), who is responsible for marketing, sales, client services, public relations, publisher network and event management. The recruiting of customers (crowdsourcers) is also managed by the CSO; (2) testCloud's Chief Operating Officer (COO), who supervises the crowd testers and is also responsible for crowd recruitment, account management and finances; (3) testCloud's Chief Technical Officer (CTO), who manages the IT-Infrastructure and the technical background of test Cloud's Internet platform.

In addition to the interviews, we reviewed several documents provided by the three interviewees such as internal data and reports. Eventually, we were also granted access to testCloud's platform. This included insight into the user-interfaces of crowdsourcers as well as of crowdsourcers. Data available on the Internet were also considered and analyzed. This is due to the fact that since commencement of business, testCloud and its underlying business concept have been a subject of discussion within the Internet start-up scene. The testCloud team has also won the 'Bitkom Innovators Pitch' award for the 'Best Digital Life Innovation in 2012.' Based on this data set we analyzed how testCloud manages different crowdsourcing projects. The findings of our study are outlined in the following section.

\subsection{Findings}

"Actually, the idea for our business emerged very naturally: We were thinking that if even companies such as Google Inc. and Facebook Inc. place high value on testing before releasing new features or applications, then there is obviously a high demand for qualitative testing. I worked for several years for a similar company, and I can say that there's a lot of interest in qualitative testing. So we asked ourselves how we could create and offer a new way of testing that would be more qualitative and efficient. We had heard a lot about approaches such as 'crowdfunding' or 'crowdcreation.' These approaches seemed to be very successful in practice, so we put our brains together and came up with the idea of crowdtesting." (testCloud-CSO).

testCloud was founded in August 2011. The start-up company denotes the services it offers as "crowdsourced software testing." In its service portfolio, this company offers functioning and quality tests for three types of software applications:

- Testing of web-applications and websites on different operating systems (Microsoft, Linux, etc.) and with different Internet browsers (Firefox, Internet Explorer, etc.).

- Testing of mobile applications on different operating systems (iOS, Android, etc.).

- Testing of client programs (CRM, BI, SaaS applications, etc.). 
This, for instance, includes: testing of e-commerce websites, social web portals, and online retail stores, as well as sales and distribution software. In contrast to existing software testing providers, testCloud obtains testing-assignments from companies, and forwards the actual testing to a crowd of testers instead of performing the testing itself. Thus, testCloud operates as an intermediary in a crowdsourcing business model connecting a vast number of testers (i.e., the crowd) with firms that aim at outsourcing the testing of their developed software. In this model, the crowd is testCloud's human resource for conducting the testing, whereas the crowdsourcing firms can be considered as the firm's customers. By leveraging the capabilities of the Internet, testCloud enables its customers to link with a vast pool of solvers. Corresponding to the theoretical explications, testCloud connects knowledge seekers-in this case software companies seeking testers-with knowledge suppliers (i.e., crowdsourcees that engage in crowd testing) and facilitates collaboration between these two parties.

The market testCloud competes with consists of several "classical" IT-Service companies that predominantly offer automated software testing; however, testCloud positions itself as one of the first companies in Germany that offers software testing by the crowd. The company performs the business process through the Internet and is active in Germany, Austria and Switzerland. By April 2012, testCloud had gathered a crowd that consisted of just over 3,000 testers. Approximately 2,000-2,100 (fluctuating number) of these testers are considered as "active testers" who regularly take part in the ongoing projects. The other 1,000 testers are active only in few projects. testCloud has initiated and fully processed 21 crowdsourcing projects by April 2012, thus maintaining a customer base consisting of multiple small and mid-sized, as well as a few large-sized, companies. From the start, testCloud has targeted upper small and medium sized internet-based, as well as large internet-based companies. However, testCloud members decided to exclude micro enterprises and very large internet-based companies as potential customers. This selection was based on the argument that very small businesses in most cases would not be able to afford a crowdsourced testing project. For instance, start-ups and micro enterprises in the IT sector consist of only a few computer scientists and they have a need for a lot of testing for their developed software (e.g., web applications); however, they do not have the monetary resources to claim crowdsourced software testing which includes expenditures for the monetary remuneration of the crowd as well as the price for testCloud's support services (e.g., costs for defining the testing requirements, costs for uploading and monitoring the contributions related to the testing project, etc.). Additionally, the testing effort is most often too excessive, e.g., the developed software inherits too many bugs since very small companies do not have the capacities to conduct upstream tests. At the top of the scale, business dealings with very large companies are also not profitable since, in these cases, the sell-cycle requires too much time and effort. This is most often on account of large companies having very tedious decision-making processes.

testCloud's first client was NETFORMIC Inc., which is an Internet agency offering its customers holistic online business solutions. testCloud was hired to test an online platform that NETFORMIC created for one of its customers. Shortly after, 
testCloud received orders from several internet-based companies, such as dating communities, social networks or online shops. In these kinds of testing projects (i.e., website-testing), the crowd usually has to conduct walkthroughs to test all the functions (e.g., the registration process or the payment transaction) of the specified platforms. Usually, most of testCloud's customers continuously, rather than just once, perform testing projects with testCloud. On the one hand, this is due to the fact that existing software applications are continuously upgraded and, thus, need to be tested perpetually. On the other hand, multiple testing projects are conducted because testCloud offers testing on different stages of the software development process, considering novel software applications.

During our analysis, it became apparent that there are three main challenges in the context of crowdsourced software testing, these are: managing the (settlement-) process, managing the crowd and managing the technology. The first dimension refers to the sequence of activities that testCloud has to perform for ensuring a smooth processing of a testing project. The second dimension encompasses all actions designated to ensure that the crowdsourcees (i.e., the crowd testers) continuously engage in the ongoing testing projects, whereas the third dimension includes the management of testCloud's online platform.

"(...) I think that managing the crowd is a big issue for us. We must continuously prove our existing, and also develop new, mechanisms with which we can control the activities of the crowd (...). The other challenge is that we need to keep track of the different activities with respect to all our different testing projects. This is basically a structured process (...). However, this process is not fully automated. We still have to manually manage different activities. We need to adjust our IT so that we can manage the process more effectively." (testCloud-CSO).

We structure the following section based on these three dimensions. Here, we will go into the different issues that we found regarding each dimension.

\subsubsection{Managing the process}

Being an intermediary in a crowdsourcing model, testCloud manages the whole crowdsourcing process-starting with the inquiry of crowdsourcers' requirements and ending with the bug export. However, various functions and activities are located in between. The critical starting point of a crowdsourced software testing project is the determination of a customer's testing requirements.

"I think that randomly testing an artifact might in some cases be very effective. Thereby, crucial pitfalls that were completely out of scope might be identified. But I also know that software companies sometimes need more 'focused' testing, and we can offer that, too. We arrange the testing requirements with our customers. For instance, we can invite the whole crowd to test a software application — be it a website or a mobile application. It can be regarding all aspects, or we can limit the testing to a set of functionalities. We denote the latter approach as the "controlled' crowd testing." (testCloud-CSO). 
At the very beginning, the customer presents the targeted software (e.g., website, mobile application) to an assigned testCloud project manager. Next, the testCloud manager and the customer elaborate on the testing requirements together: First, they determine what quality aspects are to be tested by the crowd. The software can be tested regarding different quality aspects, such as functionality, performance, loads, and security. Further, the usability as well as the interaction design can be evaluated by the crowd. The second aspect of testing requirements is defining the 'testing context': This means that the devices (e.g., Mobile Phone, Tablet PC, Notebook), the operating systems (e.g., Windows, Linux, Mac OS), and, if necessary, the browsers (Firefox, Internet Explorer, Google Chrome) on which the testing will be conducted, have to be appointed. Most often, tests are driven across all kinds of devices, operating systems and browsers, since experience shows that a software application running on one system might not work at all on another system. For instance, while testing the functionalities of a dating community, the crowd testers found that "signing in" was completely trouble-free when using a Notebook or a PC, whereas the testers were not able to sign in while using a Smart Phoneregardless of whether an Android-based phone or an iPhone was used. The third aspect that has to be determined in the initial step is the 'scope of the software testing.' The client decides how long and with how many testers from the crowd the testing phase will be conducted. Due to the circumstance that the need for testing of companies varies, depending on the urgency or the development stage of a software product, testCloud offers their customers "on-demand" solutions to guarantee a flexible service: The actual testing by the crowd can be conducted not only during business hours but also throughout the weekend or overnight. Further, customers can decide either to have their software tested in the fastest possible manner, where testing takes only several hours, or they can choose the test-phase that is conducted long-term, where the software is tested to the smallest detail by a large part of the crowd. In line with this, testCloud's customers are offered various "scales" of testing, as they can decide on the size of the crowd that can be assigned for testing. Finally, customers can alter the time-frame as well as the breadth of testing throughout the whole process, as they are constantly kept informed of the progression of the testing.

Based on the requirements, the testCloud manager and the customer elaborate 'testing guidelines' which determine the framework of the actual testing. According to our interview partners, operationalizing and clearly defining the testing requirements are critical aspects.

"We have to operationalize the tasks so that the testing can be a success. This is a very critical point, because if we don't exactly know what aspects of a software are to be tested, we cannot guide the crowd to test the aspects that our customers want to be tested (...)." (testCloud-CSO).

Based on the arranged testing requirements, testCloud is able to arrange a testing project. This includes two aspects: First, the software application to be tested has to be uploaded on the "testing platform" (i.e., the testCloud-platform). Second, the testCloud manager selects crowd testers for a specific testing project. The interviewees stress that for their customers it is important to gather the "right" 
crowd testers for specific testing projects (see statement below). Therefore, testCloud identifies and selects appropriate testers based on the determined testing requirements. For specific testing projects, software companies need rather experienced testers. In such cases, testCloud sends invitations to testers from the crowd who have gathered experience in numerous testing projects. The invited testers then self-select whether they participate in the underlying testing project.

"We have different customers with different demands. Tests for software, such as gaming and other desktop applications, are different form tests that we conduct for our business customers, considering the B2B realm. Testing of software applications for businesses is different from testing of website or gaming application-it might sometimes be much more complex. These customers ask for 'experts,' and not just 'average' users. Depending on the testing requirements that are made beforehand, the test is either available for the whole crowd or for specific members only. That means that we can choose only experienced and skilled testers for specific testing projects." (testCloudCSO).

Subsequently, testCloud activates the specific software test on the testCloudplatform and invites people from the crowd to validate the software. Here, the software to be tested is uploaded and made accessible for the crowd to test. Once a software test is activated, the crowdsourcees are allowed to walkthrough the software and identify bugs or evaluate the design and usability of the underlying software. Once a tester detects a bug, it has to be recorded and subsequently submitted on the platform. In the next step, the identified bugs, as well as comments and suggestions regarding the design and usability, are subject to stringent quality assurance by the testCloud manager. He decides which bugs will be incorporated and which ones will not. Every bug that is reported is thus first controlled by the testCloud manager in order to be assured that it really is a bug. This process is internally referred to as the quality assurance management. This enables testCloud to control crowd misbehavior-i.e., when individual crowd testers submit false findings. Hence, using testCloud as an intermediary, software companies avoid opportunistic behavior and reduce uncertainties.

"It is a very important task to ensure that customers review only bugs that actually exist. Reviewing all submitted bugs, as well as improvement suggestions, is time-extensive for us; however, this task is indispensable for establishing high quality testing." (testCloud-COO).

Finally, the customer receives a bug report in which all identified bugs are registered. The results can then be exported to the customer using any issue-tracking system, such as JIRA, Redmine, or Bugzilla. Customers are offered the possibility to trace the whole testing process and also intervene by altering their testing requirements. Thus, customers are able to continuously control the testing process on an indirect manner. Here, the customer is also offered the possibility to "countercheck" the results. According to the interviewees these two issues are crucial for the following reasons: First, these measures ensure that customers obtain demandoriented testing results. Further, customers thereby are enabled to easily embed the 
testing results within their organization. Wherever this is not the case, internal resistance within the organization might arise ("not-invented-here" behavior of internal workers).

Based on the previously attained insights, we discovered functions for each phase of the settlement process. Figure 2 graphically depicts the entire settlement process with the corresponding functions.

\subsubsection{Managing the crowd}

According to testCloud's $\mathrm{COO}$ who is responsible for crowd recruitment and crowd supervision, amongst other things, crowd management is a key issue when running a crowdsourcing intermediary. In this connection, we found that testCloud established various mechanisms for managing the challenges associated with crowd management. First, confidentially agreements play an important role in the context of crowdsourcing testing activities.

"An aspect that is very important for our customers is secrecy. For software companies, testing is a very 'sentient' topic, since no company wishes to be associated with 'bugs' or 'failures in the software development.' Further, we have projects where innovative software products are tested-software products that are not available as yet. Thus, it is extremely important that the testing projects are not spread out. Correspondingly, we instruct applicants

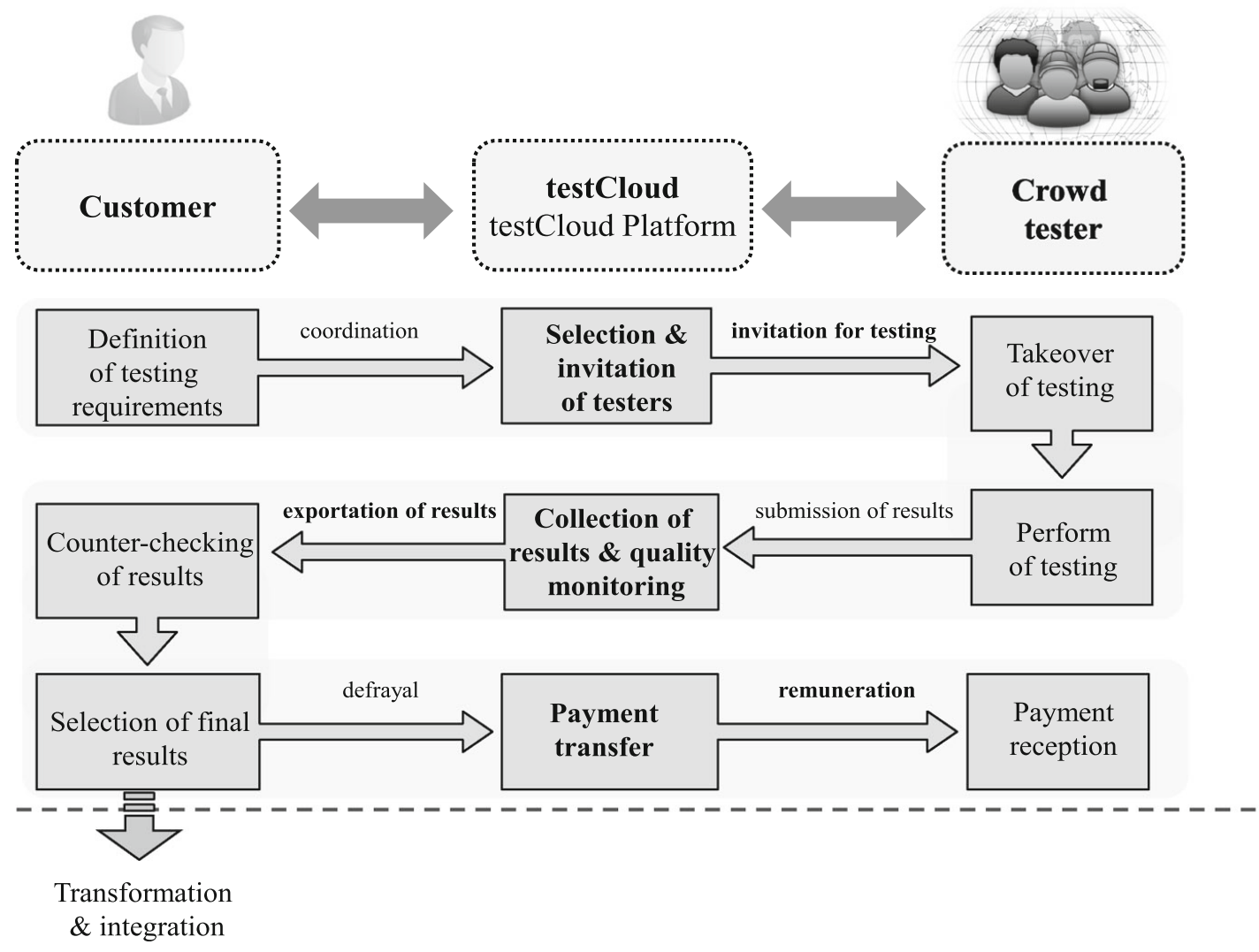

Fig. 2 Settlement process 
to undersign a non-disclosure agreement (NDA) that forbids them to publish anything that falls under the NDA. In our experience, I can say that testCloud's customers highly respect these secrecy agreements." (testCloudCSO).

Creating confidentiality and trust between the different parties-i.e., the crowd, the testCloud and the crowdsourcing company-is one of the most critical challenges that testCloud faces. For a company, sourcing out confidential tasks (such as testing) inherits the risk of losing relevant know-how. This suggests that mechanisms that ensure confidentiality have to be implemented. testCloud imposes its crowd testers on signing non-disclosure-agreements (NDAs) in order to prevent issuance of critical information. NDAs can be considered as 'hard' measures for creating confidentiality between the crowdsourcer and the crowd. On a further perspective, rather soft measures are 'crowdsourcer-crowdsourcee-meetings:' Here, the crowdsourcing company meets specific (experienced) testers from the crowd and discusses joint testing projects. In this way, trust between the company and important testers is created as both parties get to 'see the faces' behind the testing project.

Second, testCloud has to ensure that the incomes of crowdsourcees are taxed. Only individuals who prove that the incomes coming from testCloud will be recorded for tax purposes (most oft on a freelance basis) are granted access to the crowd. Third, 'gathering of demographics' is also a crucial aspect since it enables testCloud to ascertain the characteristics of the crowd. For testCloud managers to be able to distribute testing projects only to testers with prescribed characteristics (based on the previously defined testing requirements), they have to be aware of the testing experience and other demographics of crowdsourcees. Thus, applicants have to declare their demographics, their testing experience, as well as the browsers, devices and operating systems that they have used for testing.

All the above mentioned aspects (i.e., confidentially agreements, examination of tax coverage, survey of demographics) are acquired within the registration process (see Fig. 3). All individuals that apply to become a tester for testCloud have to register on the testCloud Internet platform and go through the registration process.

The submissions from the crowdsourcees (strongly) vary in quality. Thus, testCloud established different mechanisms to control the quality of submissions. Regardless of their testing experience, applicants have to go through the "testCloud Academy." Here, applicants are given instructions on how to apply for the testing, how to search for bugs and how these are recorded. Subsequently, the new members have to conduct 1-2 sample tests within 2 days. Thus, new members' skills and competencies are scrutinized based on the results of these pre-tests. However, the general rule is: The pre-tests have to at least be passed in order to become a member of that crowd. This phase is referred to the 'induction phase'. Further, testCloud offers their crowdsourcees possibilities to enhance their testing abilities. Within this so called permanent coaching, crowd testers have the chance to inter-exchange with testCloud managers or with other crowd testers.

"To ensure that also inexperienced testers provide qualitative tests, we established the 'testCloud Academy.' Each and every tester has to pass the 
(I) Registration and legal checks

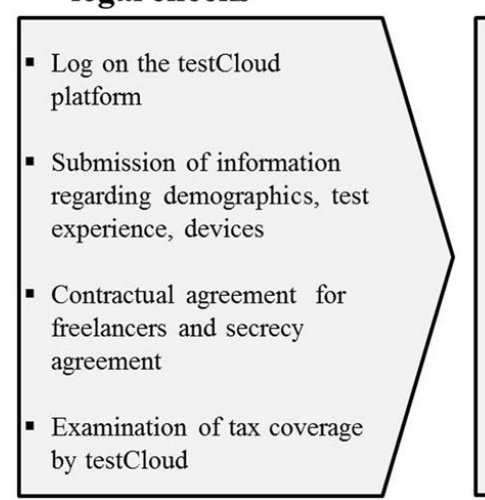

Fig. 3 Registration process
(III) Permanent coaching testCloud Academy

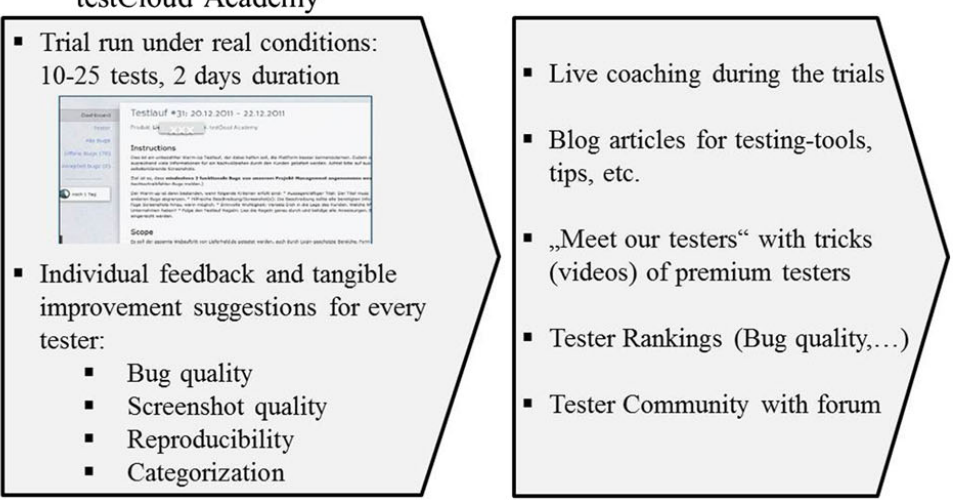

academy (...). Further, we are obliged to continuously improve the overall quality of our testing services. And that can only be realized if we raise the quality level of our testers. That's why we offer permanent coaching to our crowd members. They can, for instance, make use of our live coaching in the course of a project. That means we assist them during a project. They also have access to tutorials, or they can link with other, more experienced, testers." (testCloud-COO).

For being able to satisfy the diverse demand of their customers-ranging from software companies with specialized software to online retail companies with rather modest software applications-testCloud faces the challenge of generating $a$ diverse crowd. In order to generate a diverse crowd, testCloud had advertised in job pages of different newspapers (e.g., weekly papers) but also in subject-related magazines and online forums (e.g., computer magazines), as well as directly in universities (e.g., in the departments of informatics and information sciences). By April 2011, testCloud had established a crowd that includes just over 3,000 testers characterized by different backgrounds, personal and professional situations, experiences and testing expertise, and coming from all over Europe; however predominantly from Germany, Austria and Switzerland. Some people from the crowd have never tested a website or something similar, whereas there are also very advanced testers who have taken part in several testing projects offered by testCloud, or who are vocational testers. A survey conducted by testCloud has, for instance, shown that $22 \%$ of the crowdsourcees have had 2-5 years of experience in testing, whereas $12 \%$ have been conducted software testing for more than 5 years. $42 \%$ of the testers are students, $18 \%$ freelancers, and $26 \%$ are fulltime employed. A testing project activated by testCloud is thus exposed to a vast number of critical testers with a wide range of expertise and competencies.

The interviewees stated that a transparent remuneration system has a motivating effect for the crowd testers. Our analysis showed that motivational aspects play an important role when managing the crowd testers. According to testCloud's COO establishing effective incentive mechanisms constitutes a crucial challenge, especially when faced with a diverse crowd. 
"Our more experienced testers among the crowd members are especially highly involved in our community. These testers are very important for us. Most of them have been a part of our crowd from the beginning and have thus built up relevant testing competencies. They are the ones who find the most critical bugs, and they are the ones who find those kinds of bugs that an average tester would not be able to identify. We make every effort to keep all our crowd members highly motivated, especially the experienced testers." (testCloud-CSO).

At testCloud, all testers are paid per identified bug or per improvement suggestion-that is, once the testing project is finished and the bugs and improvement suggestions are approved by the testCloud manager and the customer. The amount that the testers are paid depends on how "critical" the identified bug is or how "appropriate and helpful" the improvement suggestion is. A bug such as “...payment per direct debit worked, but once I selected credit card payment, the website broke down..." is regarded as very critical, whereas identified spelling mistakes on a website are rather uncritical. Obviously, the more critical a bug is, the higher the payment. However, testers are only paid if the bug they have found has not previously been identified by any other tester. The policy is "first come, first served." Thus, testers are motivated to be the first to find different bugs in order to earn more money. According to testCloud's $\mathrm{COO}$ the transparency of remuneration is relevant mechanism in the context crowd governance.

"We have a transparent remuneration system. It is very important for the crowd testers to know how much they receive for a specific task. For most of our testers, testing at testCloud is a considerable additional income. I suppose testing on the side is quite appropriate, for example, for a QA-Manager who is a member of our crowd because testing is his passion, or for a housewife who intends to comfortably earn money from home." (testCloud-COO).

The interviewees stated that extrinsic motivation plays a relevant role and that most testers are motivated by monetary rewards. However, based on the results of the previously mentioned survey, intrinsic motivation is also important: Many testers report that they actually do the testing because they have fun doing it or because they like the challenge. Others like to solve problems and like the satisfaction of having solved problems. For those who are predominantly intrinsically motivated, the earned money is just a side effect and testing at testCloud can be seen as a hobby they pursue.

"We have testers that don't perform testing just because of the earnings. Some do it because they have fun testing things; or some of them want to profile themselves within our community, whereas yet others might regard the testing as a game." (testCloud-COO).

In order to satisfy the motives of these testers, testCloud implemented various artifacts, respectively functions within their platform which enable the testers to show off their competencies to the community. These aspects are outlined more in detail in the next section. 


\subsubsection{Managing the technology}

The crowdsourcing platform based on Ruby on Rails is the common interaction platform for the testCloud managers, the customers and the crowd. The entire settlement process is managed via the web-based platform. Hence, the testCloud platform builds the basis for the management of crowdtesting initiatives. However, according to testCloud's CTO the platform has been constructed based on the processes that it needs to support. The first challenge in this connection is to construct target-group oriented user-interfaces within the platform.

"We build our platform based on the processes that we need to manage (...).

We knew that we first have to construct two different user-interfaces: one for the crowd testers and one for our customers." (testCloud-CTO).

For testCloud's customers the definition and coordination of testing requirements are highly important. Hence, customers are offered functions where they can note their specific requirements: First, customers intending to set up a testing project have to determine the 'testing scenario' by defining the type of testing (e.g., functional, usability, etc.) and the testing context (e.g., only on Apple devices). Further, customers determine the testing instructions (i.e., definition of software functions to be tested), test cases (examples of how to test appropriately), further details (e.g., bug-reporting language), as well as the testing procedure (i.e., amount of testers, begin/end of project, tester requirements). The following figure illustrates the web-based artifact for recording the testing requirements (Fig. 4).

As mentioned earlier, testCloud's CTO constructed two different interfaces, which means that, e.g., the personal profile page of customers is different from that of a crowd tester. Whereas the customers are basically displayed only project relevant information (e.g., progression of a specific project), the crowd testers profile page offers more functions. First, crowd testers have a 'dashboard' on their personal profile. The dashboard visualizes a crowd tester's bug statistics-for example, the amount, and the type, of tests that have been successfully completed. The testCloud managers have access to these statistics and based on that they select crowd testers for specific testing projects. According to testCloud's CTO the testers appreciate these kinds of functions since they enable them to signalize their testing skills and competencies. Thus, the creation of such supporting functions is regarded as a main challenge in the context of managing the technology. Figure 5 shows an example of such a dashboard.

"We provide our testers the possibility to keep track of their own performance.

We can see their performance (...) these statistics are not visible for othersneither for other testers, nor for our customers. This is because we are encouraged to keep specific aspects confidential, with respect to the crowd or to our customers." (testCloud-CTO).

From our interviews with the testCloud managers, we learned that data integrity is a crucial aspect. According to the interviewees, the technology has to be constructed in a way that security holes do not exist. For testCloud's customers, on 


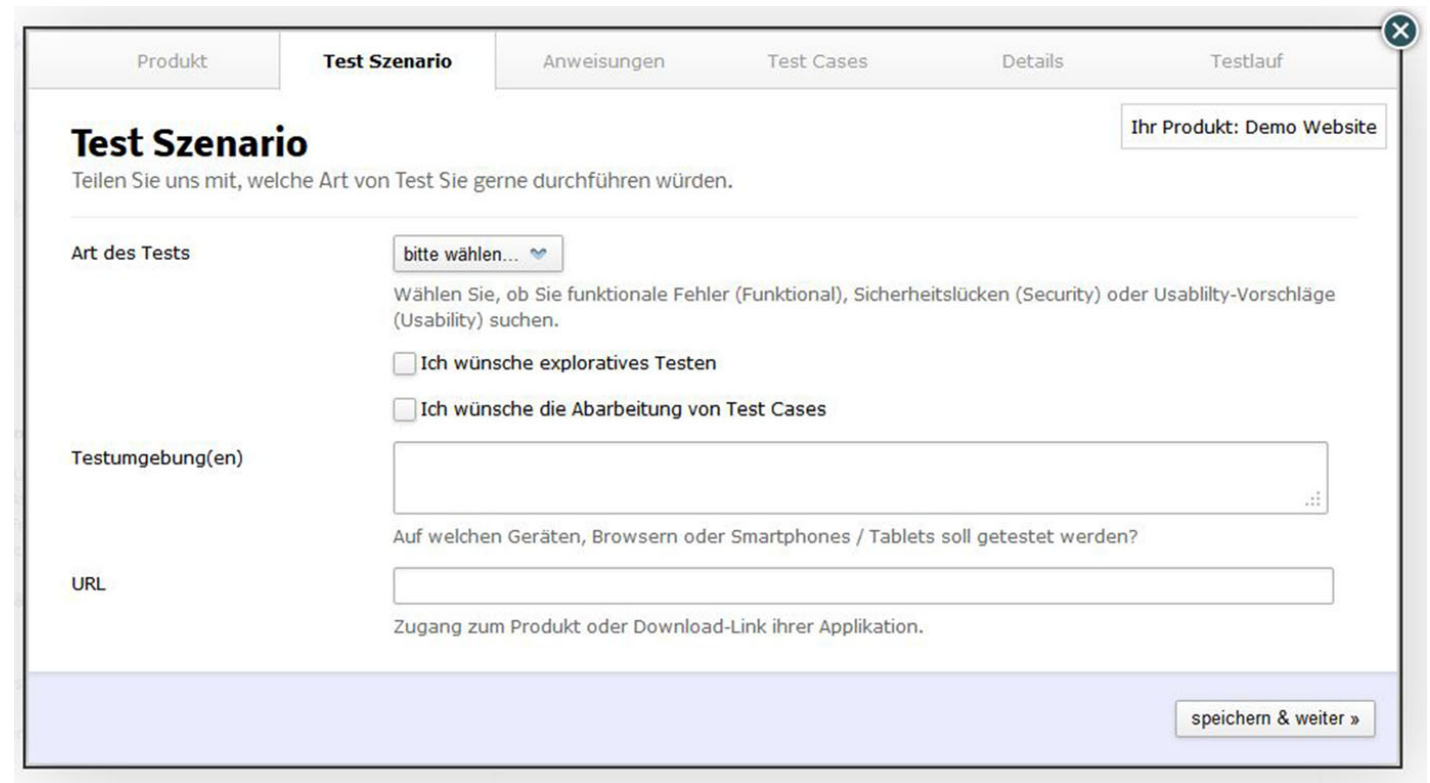

Fig. 4 Web-interface for customers - testing requirements

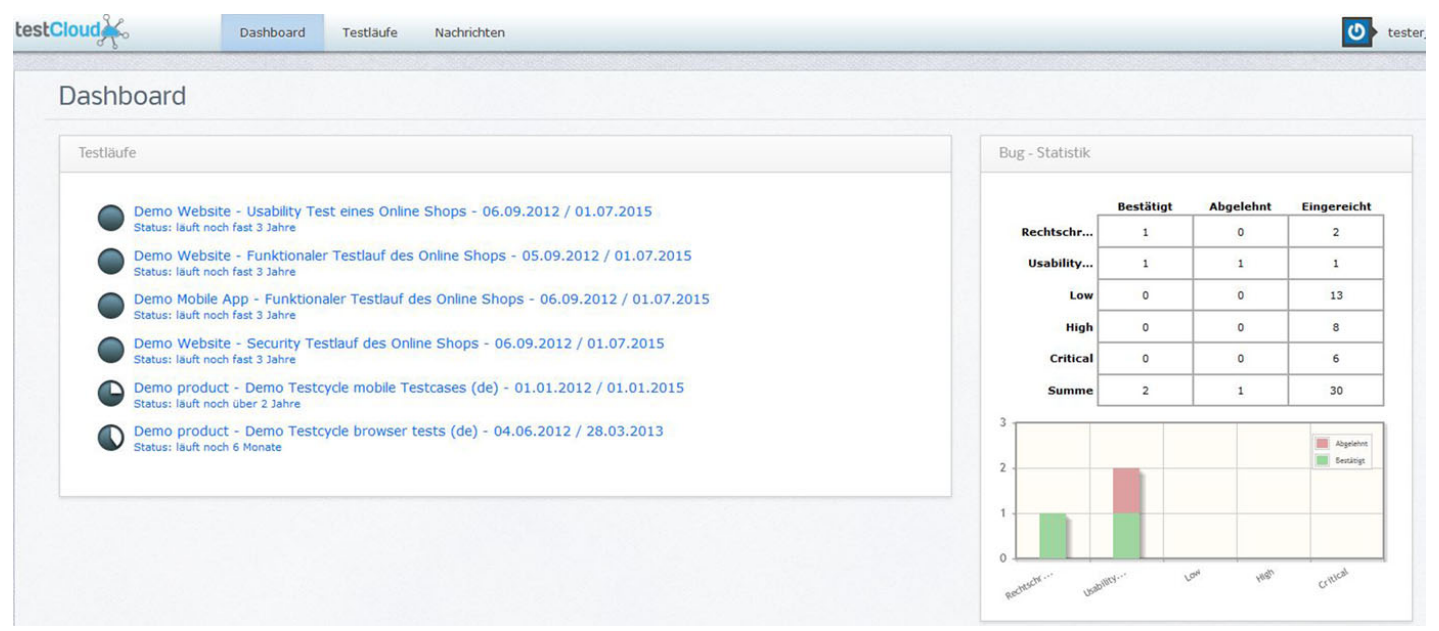

Fig. 5 Web-interface for crowd testers-Dashboard

the one hand, the testing results are confidential; on the other hand, the payment transfers are also to be secured.

"We must assure that we have no security holes in our IT-system. Especially we as a company that offers high quality crowdtesting services should not have any bugs in our system." (testCloud-CTO).

\section{Discussion and future research implications}

The case of the "testCloud" helps in exploring challenges that crowdsourcing intermediaries face when managing crowdsourcing initiatives and thereby illustrating how they manage the mediation in a crowdsourcing model. In the following, we 
discuss selected phenomena that, in our view, are crucial for understanding the crowdsourcing processes and the corresponding treatments form an intermediary's perspective. Case studies are explorative in their nature and provide first insights with respect to the analyzed phenomenon, thereby building the basis for further analyses. Therefore, we outline implications for future research with respect to the subsequently presented issues.

We found that testCloud as an intermediary in a crowdsourcing model faces three main challenges, these are: managing the (settlement-) process, managing the crowd and managing the technology. The first dimension, managing the process, encompasses procedures and treatments that testCloud implements for managing all activities in the course of a testing project. Here, we discovered functions for each phase of the settlement process. Our findings are consistent with the findings by Muhdi and Boutellier (2011a), who present generic phases of the idea generation process mediated by an open innovation intermediary. In case of crowdsourced software testing, the first challenge lies in appropriately defining the testing requirements. This measure ensures that the testing by the undefined crowd proceeds 'in the right direction.' Transferring this issue onto crowdsourcing initiatives in general, it implies that the outsourced have to be appropriately operationalized. Most research articles on crowdsourcing and human computing focus rather on breaking down a task into ever smaller micro-tasks (Quinn and Bederson 2011). However, the case study points out that strictly defining (more complex) tasks is an alternative to that procedure. Thus, future research might compare these two procedures by means of efficiency and quality of task performance.

Effectively managing the process requires also quality assurance measures. Research shows that the risk of receiving valueless outcomes out of crowdsourcing initiatives is high (see e.g., Bretschneider and Leimeister 2011). Therefore, mechanisms ensuring quality have to be incorporated with the crowdsourcing process. For instance, testCloud managers validate each submission on their own. However, future research studies might look for automated mechanisms. Another possibility is to engage the crowd in quality control. The third challenge with respect to crowdsourcing process management is the involvement of the crowdsourcers in the process, i.e., enabling crowdsourcers to monitor the testing progression, to alter requirements as desired, as well as to counter-check submissions. These measures assure that crowdsourcers attain the desired results.

The case study highlighted that for being able to manage a crowd, the crowdsourcing intermediary has to be acquainted with the concrete characteristics of crowd. In this connection, testCloud established a so called vocational adjustment process. Such a process enables testCloud to manage crowd extension on a structured manner. Further, it assures the quality of the testers since all individuals seeking to become a tester have to complete the process. This kind measure might not be necessary for micro-task crowdsourcing platforms since micro-tasks usually are of low complexity; however, it might be suitable for tasks with higher complexity, such as testing. Future research studies might compare the outcomes of crowdsourcing projects with and without such a structured vocational adjustment process. The vocational adjustment process provides the foundation for testCloud to 
be able to allocate specific testing projects to chosen testers-based on the declare demographics, testing experience, etc. The allocation of testing assignments is, however, done manually at testCloud. Future research may focus on automated recommender systems for supporting allocation activities.

The case study highlights that appropriate incentive mechanism have to be implemented for successfully managing the crowd, respectively the submissions by the crowd. The crowd testers are, hitherto, only offered monetary incentives. According to testCloud's managers, this mechanism has proven to be an appropriate incentive. This result is open to scrutiny when considering that for most crowdsourcees performing testing is regarded as an attractive way of generating an additional income. The case also revealed that the joy of testing is a relevant motivational factor as well. These insights are consistent with findings from Muhdi and Boutellier (2011b) who investigate the motivational factors for participation and collaboration in an online innovation intermediary. Their paper reveals that, in an intermediary community, motivational factors relate to "reward" are highly relevant - these are for example: 'win prizes,' 'having fun,' or 'monetary rewards for achievements.' Furthermore, the paper emphasizes the importance of motivational factors that relate to "learning" (e.g., feedback from community, feedback from company) as well. As related to testCloud, the testCloud Academy and the permanent coaching might address these motivational factors; however, this issue is to be scrutinized in further research initiatives.

However, future research might analyze changes in the outcomes when altering, or offering additional, incentive mechanisms. This might be a promising direction since various studies from other fields have demonstrated that non-monetary rewards effectively promote motivation as well. With respect to the remuneration of crowdsourcees, we also found that the transparency of compensation is important. Thereby, crowd testers have the possibility to trace their ongoing earnings, which, in turn, function as a motivational factor as well.

Finally, the third dimension, managing the technology, refers to the information systems that enable crowdtesting to be implemented by connecting the crowdsourcers and crowdsourcees via a common platform. We found that for crowdsourcing intermediaries it is advisable to provide target-group oriented interfaces-each with adapted functions. On the one hand, crowdsourcing intermediaries are to provide crowdsourcers a possibility to concretely define their requirements. testCloud acquires the requirements via a five-step survey procedure. Future research may analyze the benevolence of such approaches for acquiring customer requirements, or different approaches could be compared with each other.

On the other hand, it is also advisable to implement functions that support the work of the crowdsourcees. testCloud offers the crowd testers a possibility to trace their work performance by displaying a dashboard on the personal profiles. Apart from this, incentive supporting functions may be conceivable, i.e., functions that address different motives. For instance, Leimeister et al. (2009) analyzed different activation-supporting components for ideas communities. Hence, future research may analyze similar components for crowdtesting initiatives.

In accordance with the primary functions of intermediaries in general (see Sect. 2.2), the case stresses how testCloud mediates the connection between crowdsourcers 
and crowdsourcees in a crowdsourcing model. testCloud has established various mechanisms by means of which crowdsourcers are enabled to find appropriate partners for performing testing tasks and to outsource risks, effort and overhead related to the management of the crowdsourcing process (e.g., implementing effective incentive mechanisms, establishing an IT platform, etc.). Further, the case highlights the importance of different issues in the course of crowdsourcing intermediation, which have been emphasized by various researchers in other contexts-i.e.: IT-support (Zwass 2010), effective incentive mechanisms (Leimeister et al. 2009; Malone et al. 2010; Rouse 2010), preselection of contributors (Geiger et al. 2011), and aggregation of contributions (Schenk and Guittard 2009; Geiger et al. 2011). The case of testCloud reveals initial insights on how an intermediary in a crowdsourcing model manages these issues amongst others.

\section{Conclusion}

Crowdsourcing has gained much attention in practice over the last years. Numerous companies have drawn on this concept for performing different tasks and value creation activities. Nevertheless, despite its popularity, there is still comparatively little wellfounded knowledge on crowdsourcing, particularly with regard to crowdsourcing intermediaries. Crowdsourcing intermediaries play a key role in crowdsourcing initiatives as they assure the connection between the crowdsourcing companies and the crowd. However, hitherto, research does not provide sufficient insights regarding the management of crowdsourcing initiatives from crowdsourcing intermediaries' perspective. On this basis, this case study aims to shed light on the mediation process and the associated challenges of intermediaries in a crowdsourcing model.

First, we provided a definition of crowdsourcing and delimited this concept from outsourcing. We showed that crowdsourcing can be realized without mediation-in this case, the crowdsourcing company establishes an internal mediation platform. However, most crowdsourcing initiatives are implemented by means of crowdsourcing intermediaries, which mediate between the crowdsourcer and the crowdsourcees by providing a platform where these parties are able to interact. Subsequently, we provided theoretical background on intermediaries, in general, outlining their relevance (for firms) in overcoming insufficient skills and lack of resources. Here, we also present some prominent examples of crowdsourcing intermediaries with respect to their application fields.

In a third step, we outlined related studies in order to utilize previously generated insights for the subsequent case study. We found that various frameworks and classifications exist, which cover key issues within crowdsourcing, and which can be used to distinguish between various crowdsourcing initiatives based on the underlying dimensions.

Subsequently, we outlined a case study with a German start-up intermediary called testCloud that offers software testing services for companies intending to partly or fully outsource their testing activities to a certain crowd. We found that testCloud as an intermediary in a crowdsourcing model faces three main challenges, these are: managing the process, managing the crowd and managing the technology. 
For managers in practice the underlying study provides several mechanisms for facing the challenges associated with crowdsourcing projects. For instance, the study shows how tasks can be defined and operationalized in case of crowd testing, or how the quality of submissions can be assured. Further, we outline and present the crucial functions for each phase of the settlement process.

As for theoretical implications, this paper contributes to crowdsourcing research by providing three categories of challenges that impact the management of crowdsourcing initiatives from an intermediary's perspective. According to theory, intermediaries do not only connect knowledge seekers and knowledge suppliers but they also assist organizations in finding appropriate partners for collaboration and joint projects. Further, they help to avoid opportunistic behavior and reduce uncertainty in a multi-entity relationship, as well as to facilitate negotiations and manage networks. However, for crowdsourcing intermediaries to enable these advantages, different mechanisms have to be implemented: First, we showed that by implementing a structured registration process, testCloud is able to appropriately allocate tasks to specific crowdsourcees-hereby enabling the crowdsourcer to be connected with appropriate partners (i.e., testers). Second, testCloud reduces uncertainty within crowdsourcing initiatives by various means: the testers are obliged to sign NDA's and to conduct pre-tests for preparation. Further, crowdsourcers are enabled to monitor the testing progression, to alter requirements as desired, as well as to counter-check submissions. On the other hand, by outlining the management of submissions at testCloud, we presented measures for preventing opportunistic behavior.

In conclusion, the underlying study provides some promising insights regarding the management of crowdsourcing initiatives from an intermediary's perspective. However, the results are based on a single case study. Hence, the external validity of this case study is yet to be verified. Our case study focuses on an exemplary crowdsourcing intermediary which operates in the realm of software testing. However, there are many kinds of crowdsourcing intermediaries facing many, and often significantly different, challenges which our study may not account for. Hence, multiple case studies-also in other business segments-are needed to consolidate the herein generated outcomes. Further, testCloud is still a young company consisting of a small start-up team. These kinds of companies are usually characterized by dynamic and changing internal structures - as they naturally might also grow. Hence, future research initiatives might reveal valuable insights by scrutinizing the herein presented issues at a later point in time.

\section{References}

Afuah A, Tucci CL (2012) Crowdsourcing as a solution to distant search. Acad of Manag Rev 37(3):355-375. doi:10.5465/amr.2010.0146

Allison TH, Townsend DM (2012) Wisdom of the Crowd? Reputational cascades and emotional contagion in microlender crowdfunding. Paper presented at the 72 nd academy of management annual meeting, Boston

Bacon DF, Chen Y, Parkes D, Rao M (2009) A market-based approach to software evolution. Paper presented at the proceedings of the 24th ACM SIGPLAN conference 
Bederson B, Quinn A (2010) Web workers, unite! addressing challenges of online laborers. In: Proceedings of CHI '11 extended abstracts on human factors in computing systems, pp 97-106

Bittner E, Leimeister JM (2011) Towards CSR 2.0-potentials and challenges of Web 2.0 for corporate social responsibility communication. In: Proceedings of the 11th European academy of management annual meeting, Tallinn

Bjelland OM, Wood RC (2008) An inside view of IBM's innovation jam. MIT Sloan Manag Rev 50(1):31-40. doi:10.1225/SMR291

Blohm I, Köroglu O, Leimeister JM, Krcmar H (2012) Absorptive capacity for open innovation communities-learnings from theory and practice. Paper presented at the academy of management annual meeting

Brabham DC (2010) Moving the crowd at threadless: motivations for participation in a crowdsourcing application. Inform Commun Soc 13(8):1122-1145. doi:10.1080/13691181003624090

Brabham DC (2012) Crowdsourcing: a model for leveraging online communities. In: Delwiche A, Henderson J (eds) The Routledge handbook of participatory culture. Routledge, London, pp 1-25

Brandel M (2008) Crowdsourcing: are you ready to ask the world for answers? Computerworld 42:24-26

Bretschneider U (2012) Die Ideen-Community zur Integration von Kunden in den Innovationsprozess: Empirische Analysen und Implikationen. Dissertation. Gabler, Wiesbaden. doi:10.1007/978-3-83497173-9

Bretschneider U, Leimeister JM (2011) Schöne neue Crowdsourcing Welt: Billige Arbeitskräfte, Weisheit der Massen? In: Meißner K, Engelien M (eds) Virtual enterprises, communities and social networks, Proceedings zum Workshop Gemeinschaft in Neuen Medien (GeNeMe 11). Dresden, pp 1-13

Bullinger AC, Neyer AK, Rass M, Möslein KM (2010) Community-based innovation contests: where competition meets cooperation. Creativ Innov Manag 19(3):290-303. doi:10.1111/j.1467-8691. 2010.00565.x

Burger-Helmchen T, Penin J (2010) The limits of crowdsourcing inventive activities: What do transaction cost theory and the evolutionary theories of the firm teach us? Paper presented at the workshop on open source innovation, Strasbourg

Burt RS (2005) Brokerage and closure: An introduction to social capital. Oxford University Press, New York. doi:10.1093/esr/jcm030

Caraway B (2010) Online labour markets: an inquiry into oDesk providers. Work Organ Labour Global 4(2):111-125

Chanal AV, Caron-Fasan M (2010) The difficulties involved in developing business models open to innovation communities: the case of a crowdsourcing platform. Manag 13(4):318-340. doi:10.3917/ mana.134.0318

Chesbrough H, Crowther A (2006) Beyond high tech: early adopters of open innovation in other industries. R\&D Manag 36(3):229-236. doi:10.1111/j.1467-9310.2006.00428.x

Corney JR, Torres-Sanchez C, Jagadeesan AP, Regli WC (2009) Outsourcing labour to the cloud. Int J Innov Sustain Develop 4(4):294-313. doi:10.1504/IJISD.2009.033083

Darke P, Shanks G, Broadbent M (1998) Successfully completing case study research: combining rigour, relevance and pragmatism. Inform Syst J 8(4):273-289. doi:10.1046/j.1365-2575.1998.00040.x

Doan A, Ramakrishnan R, Halevy AY (2011) Crowdsourcing systems on the World-Wide Web. Commun ACM 54:86-96. doi:10.1145/1924421.1924442

Eisenhardt KM (1989) Building theories from case study research. Acad Manag Rev 14(4):532-550. doi:10.5465/AMR.1989.4308385

Ernst H (2002) Success factors of new product development: a review of the empirical literature. Intern J Manag Rev 4(1):1-40. doi:10.1111/1468-2370.00075

Estellés-Arolas E, González-Ladrón-de-Guevara F (2012) Towards an integrated crowdsourcing definition. J Inform Sci 38(2):189-200. doi:10.1177/0165551512437638

Faste H (2011) Opening “open” innovation. In: DPPI '11 proceedings of the 2011 conference on design pleasurable products and interfaces

Franke N, Piller F (2004) Value creation by toolkits for user innovation and design: the case of the watch market. J Prod Innov Manag 21:401-415. doi:10.1111/j.0737-6782.2004.00094.x

Füller J, Matzler K (2007) Virtual product experience and customer participation-a chance for customer-centred, really new products. Technovation 27(6-7):378-387. doi:10.1016/j.technovation. 2006.09.005

Füller J, Hutter K, Faullant R (2011) Why co-creation experience matters? Creative experience and its impact on the quantity and quality of creative contributions. R\&D Manag 41(3):259-273. doi:10. 1111/j.1467-9310.2011.00640.x 
Gassmann O, Enkel E (2004) Towards a theory of open innovation: three core process archetypes. Paper presented at the R\&D management conference (RADMA), Lissabon

Geiger D, Seedorf S, Schulze T, Nickerson R, Schader M (2011) Managing the crowd: towards a taxonomy of crowdsourcing processes. In: Proceedings of the 7th American conference on information system, Detroit

Hartley SE (2010) Kiva.org: crowd-sourced microfinance and cooperation in group lending working paper, 25 March 2010 Available at SSRN: http://ssrn.com/abstract=1572182

Hoßfeld T, Hirth M, Tran-Gia P (2012) Aktuelles Schlagwort: crowdsourcing. Inf Spek 35(3):204-208. doi:10.1007/s11576-012-0321-7

Howe J (2006a) Crowdsourcing: a definition. http://crowdsourcing.typepad.com/cs/2006/06/ crowdsourcing_a.html. Accessed 18 May 2012

Howe J (2006b) The rise of crowdsourcing. Wired Mag 14(6):1-4

Howe $\mathbf{J}$ (2008) Crowdsourcing. Why the power of the crowd is driving the future of business. Crown Business Publishing, New York

Howells J (2006) Intermediation and the role of intermediaries in innovation. Res Policy 35:715-728. doi:10.1016/j.respol.2006.03.005

Jain R (2010) Investigation of governance mechanisms for crowdsourcing initiatives. Paper presented at the AMCIS 2010 proceedings

Jayakanthan R, Sundararajan D (2011) Enterprise crowdsourcing solutions for software development and ideation. Paper presented at the proceedings 2 nd international workshop on ubiquitous crowdsouring

Jeppesen LB, Lakhani KR (2010) Marginality and problem-solving effectiveness in broadcast search. Organ Sci 21(5):1016-1033. doi:10.1287/orsc.1090.0491

Kaufmann N, Schulze T, Veit D (2011) More than fun and money. Worker motivation in crowdsourcing - a study on mechanical turk. In: Proceedings of the 7th AMCIS, Detroit

Kirkels Y, Duysters G (2010) Brokerage in SME networks. Res Policy 39:375-385. doi:10.1016/j.respol. 2010.01.005

Kleeman F, Voss GG, Rieder K (2008) Un(der)paid innovators: the commercial utilization of consumer work through crowdsourcing. Sci Tech Innov Stud 4(1):5-26

Klerkx L, Leeuwis C (2009) Establishment and embedding of innovation brokers at different innovation system levels: insights from the Dutch agricultural sector. Tech Forecast Soc Change 76:849-860. doi:10.1016/j.techfore.2008.10.001

Lakhani KR, Wolf B (2005) Why hackers do what they do. Understanding motivation and effort in free/ open source software projects. In: Feller J, Fitzgerald B, Hissam S, Lakhani KR (eds) Perspectives on free and open source software. The MIT Press, Cambridge. doi:10.2139/ssrn.443040

Lakhani KR, Jeppesen LB, Lohse PA, Panetta JA (2007) The value of openness in scientific problem solving. Harvard Business School Working Paper No 07-050 [Online] http://www.hbs.edu/research/ pdf/07-050pdf

Leimeister JM (2010) Collective intelligence. Bus Inf Syst Eng 4(2):245-248. doi:10.1007/s12599-0100114-8

Leimeister JM, Huber M, Bretschneider U, Krcmar H (2009) Leveraging crowdsourcing: activationsupporting components for IT-based ideas competition. J Manag Inf Syst 26(1):197-224. doi:10. 2753/MIS0742-1222260108

Malone TW, Laubacher R, Dellarocas C (2010) The collective intelligence genome. MIT Sloan Manag Rev 51(3):20-31

Malone T, Laubacher R, Johns T (2011) The big idea: the age of hyperspecialization. Harvard Bus Rev, July-August, pp 1-11. http://www.topcoder.com/wp-content/uploads/2011/09/Hyperspecialization. pdf. Accessed 13 June 2012

Mao K, Yang Y, Li M, Harman M (2013) Pricing Crowdsourcing-Based Software Development Tasks. Paper presented at the 26th international conf on software engineering, San Francisco

Meredith J (1998) Building operations management theory through case and field research. J Operat Manag 16(4):441-454. doi:10.1016/S0272-6963(98)00023-0

Muhdi L, Boutellier R (2011a) The crowdsourcing process: an intermediary mediated idea generation approach in the early phase of innovation. Int J Entrepren Innov Manag 14(4):315-332. doi:10.1504/ IJEIM.2011.043052

Muhdi L, Boutellier R (2011b) Motivational factors affecting participation and collaboration of members in two different Swiss Innovation communities. Int J Innov Manag 15(3):543-562. doi:10.1142/ S1363919611003477

Myers GJ, Sandler C, Badgett T (2011) The art of software testing. New Jersey 
Oliveira F, Ramos I, Santos L (2010) Definition of a crowdsourcing innovation service for the European SMEs. In: Daniel F, Facca FM (eds) Current trends in web engineering. Springer, Heidelberg

Paulini M, Murty P, Maher ML (2012) Understanding collective design communication in open innovation communities. Working Paper. University of Sydney, Australia

Pénin J (2008) More open than open innovation? Rethinking the concept of openness in innovation studies. Paper presented at the DT BETA, Strasbourg

Quinn AJ, Bederson BB (2011) Human computation: a survey and taxonomy of a growing field. Paper presented at the CHI 2011-proceed of the SIGCHI conference, Vancouver, May 7-12

Rayna T, Striukova L (2010) Large-scale open innovation: open source vs. patent pools. Int J Techn Manag 52(3, 4):477-496

Riungu-Kalliosaari L, Taipale O, Smolander K (2012) Testing in the cloud: exploring the practice. IEEE Softw 29(2):46-51. doi:10.1109/MS.2011.132

Rouse AC (2010) A Preliminary taxonomy of crowdsourcing. In: Australian conference on information system (ACIS), Brisbane, 1-3 Dec 2010

Schenk E, Guittard C (2009) Crowdsourcing: what can be outsourced to the crowd, and why? In: HAL: sciences de l'Homme et de la Société

Schenk E, Guittard C (2011) Towards a characterization of crowdsourcing practices. J Innov Econ 7(1):93-107. doi:10.3917/jie.007.0093

Steinfield C, Markus ML, Wigand RT (2011) Through a glass clearly: standards, architecture, and process transparency in global supply chains. J Manag Inform Sys 28(2):75-108. doi:10.2753/MIS07421222280204

Stewart J, Hyysalo S (2008) Intermediaries, users and social learning in technological innovation. Int J Innov Manag 12(3):295-325. doi:10.1142/S1363919608002035

Surowiecki J (2004) The wisdom of crowds: why the many are smarter than the few and how collective wisdom shapes business, economies, societies, and nations, 1st edn. Doubleday Books, New York

Tapscott D, Williams AD (2007) Wikinomics: how mass collaboration changes everything. New York. doi:10.1111/j.1468-0270.2008.864_2.x

Tung Y-H, Tseng S-S (2013) A novel approach to collaborative testing in a crowdsourcing environment. J Syst Softw 86(8):2143-2153. doi:10.1016/j.jss.2013.03.079

Verner JM, Abdullah LM (2012) Exploratory case study research: outsourced project failure. Inform Softw Technol 54(8):866-886. doi:10.1016/j.infsof.2011.11.001

von Hippel E (1986) Lead users: a source of novel product concepts. Manag Sci 32(7):791-805. doi:10. 1287/mnsc.32.7.791

Vukovic M (2009) Crowdsourcing for Enterprises. Paper presented at the SERVICES '09 proceedings of the 2009 congress on services-I, Los Angeles

Vukovic M, Bartolini C (2010) Towards a research agenda for enterprise crowdsourcing. In: Margaria T, Steffen B (eds) Leveraging Applications of formal methods, verification, and validation, Lecture notes in computer science, vol 6415. Springer, Berlin Heidelberg, pp 425-434. doi:10.1007/978-3-642-16558-0_36

Walmsley A (2009) The art of delegation. Marketing, 22 July 2009, pp 12-12 (1 page)

Ward C, Ramachandra V (2010) Crowdfunding the next hit: microfunding online experience goods. Workshop on computational social science and the wisdom of crowds (NIPS 2010). http://people.cs. umass.edu/ wallach/workshops/nips2010css/papers/ward.pdf. Accessed 20 July 2012

West J, Lakhani K (2008) Getting clear about communities in open innovation. Ind Innov 15(2):223-231

Whitla P (2009) Crowdsourcing and its application in marketing activities. Contem Manag Res 5(1):15-28

Whittaker JA (2000) What is software testing? And why is it so hard? IEEE Softw 17(1):70-79. doi:10. $1109 / 52.819971$

Winch GM, Courtney R (2007) The organization of innovation brokers: an international review. Technol Analy Strategy Manag 19:747-763. doi:10.1080/09537320701711223

Yin RK (2003) Case study research: design and methods, vol 5. Applied social research methods series, 3rd edn. Sage Publications, Thousand Oaks. doi:10.1111/j.1540-4781.2011.01212_17.x

Yuen M-C, King I, Leung K-S (2011) A survey of crowdsourcing systems. Paper presented at the 2011 IEEE international conference on privacy, security, risk, and trust, Boston

Zhao Y, Zhu Q (2012) Evaluation on crowdsourcing research: current status and future direction. Inf Syst Front. doi:10.1007/s10796-012-9350-4

Zwass V (2010) Co-creation: toward a taxonomy and an integrated research perspective. Int J Electr Com 15(1):11-48. doi:10.2753/JEC1086-4415150101 